\title{
Incentives for Clinical Trials
}

\author{
Erik Grönqvist* Douglas Lundin**
}

September 25, 2006

SSE/EFI Working Paper Series in Economics and Finance No. 636

\begin{abstract}
Who gains from more information on the quality of pharmaceutical drugs? Are there incentives for voluntary post-approval clinical trials among pharmaceutical companies? Contrary to popular belief, this paper shows that it is not in the consumer interest that clinical evidence establishing the relative effectiveness within a class of drugs are produced. Pharmaceutical companies, on the other hand, do benefit: the elimination of uncertainty regarding quality increases expected product differentiation, thereby raising prices for both high-quality and low-quality drugs, to the disadvantage of consumers.

Still there is no unique equilibrium where the market provides clinical trials. If the costs of carrying out clinical trials are small, in relative terms, there will be a coordination problem between firms, as firms will want a rival firm to carry the cost. If the costs are large they will be prohibitive. Legislation that obligates entering firms to carry out post-approval trials is beneficial for firms if it solves the coordination problem, but is otherwise harmful. Legislation is never in the interest of consumers.
\end{abstract}

Key words: Quality uncertainty, Symmetric information, Pharmaceutical market, Clinical trial

JEL-codes: D81, D83, I18, L15

\footnotetext{
${ }^{*}$ Centre for Health Economics, Department of Economics, Stockholm School of Economics, P.O. Box 6501, SE-113 83 Stockholm, Sweden, e-mail: erik.gronqvist@hhs.se

** Pharmaceutical Benefits Board, P.O. Box 55, SE-171 11 Solna, Sweden, e-mail: douglas.lundin@lfn.se
} 


\section{Introduction}

A commonly held view in the policy debate and the medical community is that too few well performed post-approval clinical trials - so-called Phase IV trials - are carried out; i.e., clinical trials that really establish the relative effectiveness within a class of drugs (e.g. Angell 2004, and Bernstein and Bernstein 2006). There is no regulation requiring drug companies to do Phase IV trials ${ }^{1}$, and drug companies are believed to have no incentives to voluntarily carry out informative trials. Consumers, on the other hand, are believed to have much to gain from more information on drug effectiveness. Marcia Angell-former editor-in-chief at New England Journal of Medicine - argues in a widely spread book that the market left to its own will provide too few well designed post-approval clinical trials that directly compare one drug with another: "The last thing drug companies want is a head-to-head comparison with older drugs" (Angell, 2004, p. 98). ${ }^{2}$ She therefore strongly advocates legislation that obliges entrant firms to carry out such clinical trials when launching a new drug.

In this paper we show, in a theoretical model with symmetric quality uncertainty, that in fact the opposite is true: it is not in the interest of consumers that informative clinical trials are carried out. Drug companies, on the other hand, increase their expected profits by performing trials that reveal which drug is better, unless the cost for carrying out trials is too high. That is, there is no strategic reason for companies to keep quality uncertain. A legislation that requires companies to carry out such clinical trials - as recommended by Angell-will never benefit consumers. It may however benefit firms as it can solve a coordination problem where firms want their rivals to carry the cost of a clinical trial. If trial costs are sufficiently high, on the other hand, legislation forces firms to perform unprofitable trials, which can hamper pharmaceutical development.

The basic reason firms increase their expected profits by performing Phase IV trials is that it helps them differentiate their products from their competitors'. What non-economists may not realize, is that in oligopolistic markets it is the differences in quality between products that determine prices and profits, rather than the level of quality; that is, it is worse for a firm to produce a drug with the same quality as the competitor, than to produce a drug with a lower quality. From a consumer perspective clinical trials drive up prices by differentiating products

\footnotetext{
${ }^{1}$ However, it is increasingly common that the Food and Drug Administration (FDA) requires companies to conduct confirmatory studies just to make sure the new drug is safe. In fact, about two-thirds of all new molecular entities approved in 2000 were supposed to undergo Phase IV studies for follow up on safety (Angell, 2004, p. 163).

${ }^{2}$ To establish the relative effectiveness of drugs a head-to-head clinical trial is generally needed.
} 
without increasing expected quality in the market. Trials naturally reduce uncertainty, but the price effect dominates.

That clinical trials are important as an instrument to improve profitability is supported empirically by Azoulay (2002), who finds that results from clinical trials have positive effects on profits. Our paper provides a theoretical explanation for these empirical findings; i.e., why clinical research after approval may be beneficial to firms.

Anecdotal evidence from the industry also indicates that pharmaceuticals might gain when quality uncertainty is unveiled. For example, extensive head-to-head clinical trials have been carried out between Nexium (esomeprazol) - AstraZeneca's ulcer and heartburn drug of proton pump inhibitor type - and other proton pump inhibitors. For some uses Nexium is shown to be better (Castell et al 2002; Kahrilas et al, 2001; Labenz et al, 2003; Richter et al 2001), whereas for other uses it is not (Armstrong, 2004). It has been a clear advantage to AstraZeneca that Nexium is better in some instances, since it has allowed them to charge a much higher price. ${ }^{3}$ However, it is questionable whether this has been of benefit to consumers, since less uncertainty comes with a higher price.

The theoretical case for why firms wish to differentiate their products vertically is well established (see Gabszewicz and Thissé 1979, 1980; Shaked and Sutton, 1982). We add to the analysis by noting that the elimination of quality uncertainty increases product differentiation, as ex-post realizations by definition are more extreme than ex-ante expectations over potential outcomes. ${ }^{4}$

Previous papers have addressed the issue of uncertain product quality in an asymmetric information context (e.g. Bagwell and Riordan 1991, Riordan 1986, Rogerson 1988, Wolinsky 1983, and Bester 1998). In our model, however, information is symmetric; that is, neither part knows the quality before the trial is performed. We do not believe that the main informational problem in the market for prescription drugs concerns asymmetric information. ${ }^{5}$ Instead

\footnotetext{
${ }^{3}$ If they had not shown that they were better than Losec (omeprazol), they would have had to cut their price approximately 50 percent on the Swedish market, as indicated by a report from the Swedish Pharmaceutical Benefits Board (2006).

${ }^{4}$ This follows from the same logic as the standard error of a mean estimate is always smaller than the standard deviation of the population.

${ }^{5}$ Asymmetric information could exist to the extent that pharmaceutical firms are better informed about the efficacy and side effects of their drug, than patients and doctors are. This is probably usually the case. Doctors do not have the time to fully inform themselves about what has been shown in clinical research about each drug, and most patients do not have the knowledge to process the information even if they had the time. Information asymmetry could also be due to selective reporting of results from clinical research, which there has been evidence of, e.g. Melander et al (2003).
} 
there is major aggregate uncertainty, where neither firms, nor doctors nor patients know for certain which drug is more effective. A major reason for this is that long term effects cannot be detected until the drug has been in long term use.

The paper proceeds as follows. The next section presents the set-up of the model, and derives and compares profits with and without informative clinical trials. Section three compares consumer surpluses with and without trial. The final section concludes and discusses the results.

\section{Profits}

In order to address whether pharmaceutical firms have an incentive to carry out voluntary clinical trials, expected ex-ante profits when a trial is carried out will here be compared to profits when a trial is not carried out. Before profits are calculated, though, the structure of the model must be outlined. The setting is similar to Gabszewicz and Thissé $(1979,1980)$ and Shaked and Sutton $(1982,1983)$ but introduces uncertainty in qualities in the context of pharmaceutical markets.

We first assume that the effectiveness of a drug that has been registered by the drug approval authorities, e.g. FDA (or EMEA in the EU), is still uncertain as it enters the market, and that the ignorance is symmetric among producers and patients. The uncertainty is assumed to be possible to resolve through a Phase IV study only; that is, through a voluntary clinical trial taking place after registration.

Next, consider that an agent with a certain realized health condition faces the following quasi-linear utility

$$
u=\theta h^{\alpha}+Y-P
$$

where he gains utils from general consumption, $\mathrm{Y}$, and from consuming one unit of a pharmaceutical drug of quality $h$, for which he pays a price $P$. The first term in the utility function can be characterized as the health-related utility generated by the drug. Preference for drugs, $\theta$, differs across agents and is uniformly distributed across the population $\theta \sim U(\bar{\theta}, \underline{\theta})$. Patients with larger values of $\theta$ receive higher health-related utility from a drug of a certain quality $h$. The only difference among patients is the heterogeneity in the preference parameter $\theta$.

In the pharmaceutical market for this particular condition there are two firms producing one drug each. An incumbent firm $i$ is producing a drug of known quality $h_{i}$, as it has been in the market sufficiently long for its quality to have been resolved through earlier Phase IV trials. The incumbent is now facing new competition from an entrant firm $j$ producing a drug 
with unknown quality. The quality of drug $j$ is assumed to be distributed dichotomously; that is, quality is either realized as low, $\underline{h}_{j}$, or as high, $\bar{h}_{j}$. Information on $\underline{h}_{j}, \bar{h}_{j}$, and on the probability of quality being low, $p$, is known from inconclusive Phase III studies upon which registration is based. Based on this information patients form expectations of the health-related utility obtained from consuming drug $j$; i.e., $E\left(h_{j}^{\alpha}\right)=p \underline{h}_{j}^{\alpha}+(1-p) \bar{h}_{j}^{\alpha}{ }^{6}$

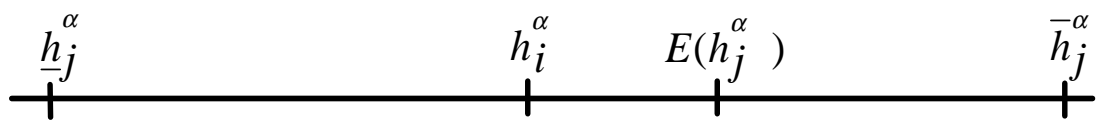

Figure 1: The distribution of quality.

The entrant, firm $j$, is assumed to enter the market only when it captures the upper end of the market; that is, when firm $j$ can charge a higher price for its drug than can firm $i$, i.e. when $P_{j}>P_{i}$-which it can if drug $j$ provides a higher health-related utility, $E\left(h_{j}^{\alpha}\right)>h_{i}^{\alpha}$. ${ }^{7}$ The decision problem, facing both firms, is whether to resolve the quality uncertainty of drug $j$ by performing a Phase IV trial. ${ }^{8}$

If the trial is done and $\bar{h}_{j}$ is realized, firm $j$ continues to sell to the upper end of the market and firm $j$ to the lower end of the market, but the difference in product quality will be larger than the expected difference before the trial. If, on the other hand, $\underline{h}_{j}$ is realized then firm $j$ will now sell to the lower end of the market while firm $i$ will instead sell to the upper end of the market. We also assume that performing a clinical trial also carries a cost, $\Omega$, that firms will have to take into account. Costs for clinical trials can be a substantial part of total development costs for a project (Dimasi, Hansen and Grabowski, 2003).

The timing of events is as follows; firm $j$ has just entered and captured the upper end of the market, based on the expectations on $\operatorname{drug} j$. Now, either of the two firms can decide whether to resolve the uncertainty through a Phase IV trial.

Next, we will calculate and compare the profits if no trial is performed with the expected ex-ante profits if at least one of the firms decides to resolve the uncertainty.

\footnotetext{
${ }^{6}$ Letting quality of both drugs be unknown, or letting the distribution of quality be continuous, will not change the qualitative results in the analysis.

${ }^{7}$ This assumption comes from the empirical observation that few, if any, new drugs-based on new chemical entities - are launched with the scope to capture the lower end of the market. Still, the model can be extended to include the case when $P_{j}<P_{i}$-i.e. when $E\left(h_{j}^{\alpha}\right)<h_{i}^{\alpha}$-but this does not change the qualitative results, see Appendix.

${ }^{8}$ In the present context we abstract from the distinction between head-to-head trials and trials aganist placebo.
} 


\subsection{Not resolving uncertainty: No clinical trial}

When neither firm performs a Phase IV trial the exact quality of drug $j$ will remain uncertain; with probability $p$ the quality is low and with $1-p$ it is high. Equilibrium profits in the market will therefore depend on the expectations of drug $j$ 's quality.

The first step in finding market equilibrium is to define the demand functions for drug $i$ and $j$. We first note that the expected utility of drug $j$ for an agent with preferences $\theta$ is

$$
\begin{aligned}
E\left(u_{j}^{N T}\right) & =p\left(\theta \underline{h}_{j}^{\alpha}+Y-P_{j}\right)+(1-p)\left(\theta \bar{h}_{j}^{\alpha}+Y-P_{j}\right) \\
& =\theta E\left(h_{j}^{\alpha}\right)+Y-P_{j}=\theta \widetilde{h}_{j}^{\alpha}+Y-P_{j},
\end{aligned}
$$

where $N T$ denotes no trial. For convenience the expected health-related utility gain from drug $j, E\left(h_{j}^{\alpha}\right)$, is replaced with its certainty equivalent, $\widetilde{h}_{j}^{\alpha}$; that is, the certain quality level that provides an agent with the same utility as the expected quality, i.e. $\widetilde{h}_{j}^{\alpha}=E\left(h_{j}^{\alpha}\right)$ where $\widetilde{h}_{j}<E\left(h_{j}\right)$. Now, an agent choosing between drugs $i$ and $j$ will be indifferent to the two if they provide him with the same level of utility

$$
\begin{aligned}
E\left(u_{j}^{N T}(\theta)\right) & =u_{i}^{N T}(\theta) \\
\theta \widetilde{h}_{j}^{\alpha}+Y-P_{j} & =\theta h_{i}^{\alpha}+Y-P_{i} \\
& \Rightarrow \widehat{\theta}=\frac{P_{j}-P_{i}}{\widetilde{h}_{j}^{\alpha}-h_{i}^{\alpha}},
\end{aligned}
$$

which defines $\widehat{\theta}$, the preferences of the marginal individual who is indifferent to the two drugs. Patients with preferences $\theta>\widehat{\theta}$ will consume drug $j$ whereas those $\theta<\widehat{\theta}$ will consume drug $i$. From equation (3) it follows that firm $j$ serves the higher end of the market - charges a higher price $P_{j}-P_{i}>0$ - only when the (expected) health-related utility generated by drug $j$ is higher than the (certain) gain provided by drug $i$. In other words, the demand for drugs $i$ and $j$ respectively is defined as $D_{j}^{N T}\left(P_{i}, P_{j}\right)=\bar{\theta}-\widehat{\theta}=\bar{\theta}-\left(P_{j}-P_{i}\right) /\left(\widetilde{h}_{j}^{\alpha}-h_{i}^{\alpha}\right)$ and $D_{i}^{N T}\left(P_{i}, P_{j}\right)=\widehat{\theta}-\bar{\theta}=\left(P_{j}-P_{i}\right) /\left(\widetilde{h}_{j}^{\alpha}-h_{i}^{\alpha}\right)-\bar{\theta}$.

In market equilibrium firms $i$ and $j$ maximize

$$
\max _{P_{k}} \pi_{j}^{N T}=\left(P_{k}-c\right) D_{k}^{N T}\left(P_{i}, P_{j}\right)
$$

where $k=i, j$. By taking first order conditions the equilibrium prices are obtained as

$$
\begin{aligned}
& P_{j}^{N T}=c+\frac{(2 \bar{\theta}-\underline{\theta})}{3}\left(\widetilde{h}_{j}^{\alpha}-h_{i}^{\alpha}\right), \\
& P_{i}^{N T}=c+\frac{(\bar{\theta}-2 \underline{\theta})}{3}\left(\widetilde{h}_{j}^{\alpha}-h_{i}^{\alpha}\right) .
\end{aligned}
$$


If the value of drug $i$ 's and $j$ 's quality is the same-i.e. if they generate the same health related utility - there will be a fierce price competition driving both prices down to the marginal production $\operatorname{cost} c$. Any mark-up over marginal production cost, $c$, will thus be generated by differences in the value of perceived or realized qualities. As quality differentiation grows larger both firms experience an increasing market power and thus higher mark-ups. Note that firm $j$-serving the upper end of the market-has a larger mark-up. If $\widetilde{h}_{j}$ is increased, ceteris paribus, the price of drug $j$ will increase both because of (i) laxer competition and (ii) a larger relative quality advantage of drug $j$; as consumers are prepared to pay for a higher relative quality. For drug $i$ the laxer competition dominates over the reduced relative quality effect, and thus the price of $\operatorname{drug} i$ increases with a higher perceived quality of drug $j$; i.e., with higher $\widetilde{h}_{j}$. In order for the market to have room for both a high and a low quality brand-i.e. for the price of drug $i$ to be positive - there has to be sufficient heterogeneity among consumers $\bar{\theta}>2 \underline{\theta}$.

By substituting equations (4) and (5) into the characterization of the marginal consumer, equation (3), we find that

$$
\widehat{\theta}=\frac{\bar{\theta}+\underline{\theta}}{3},
$$

the relative location, i.e. the characteristics, of the marginal consumer only depends on the heterogeneity of consumers - a primitive of the model setup - and the equilibrium profits for the two firms therefore become

$$
\begin{aligned}
\pi_{j}^{N T} & =\frac{(2 \bar{\theta}-\underline{\theta})^{2}}{9}\left(\widetilde{h}_{j}^{\alpha}-h_{i}^{\alpha}\right), \\
\pi_{i}^{N T} & =\frac{(\bar{\theta}-2 \underline{\theta})^{2}}{9}\left(\widetilde{h}_{j}^{\alpha}-h_{i}^{\alpha}\right) .
\end{aligned}
$$

Profits for both firms are increasing with differences in perceived and realized qualities, and for a given difference in quality firm $j$ earns higher profits than firm $i$. These are standard results in oligopoly models with vertical production differentiation, see for example Tirole (1988).

\subsection{Resolving uncertainty: Clinical trial}

The quality of drug $j$ does not have to be uncertain, since both firm $i$ and $j$ have the possibility to perform a Phase IV study. It would be beneficial for a firm if uncertainty were resolved only if this would increase the firm's profits in expectation. When the uncertainty is removed, firm $j$ 's quality is either realized as high $\left(\bar{h}_{j}\right)$ or as low $\left(\underline{h}_{j}\right)$, and in order to find the expected profits we first have to calculate market profits in the different realizations and then take 
expectations over the realizations. We will initially disregard the cost, $\Omega$, of performing a trial.

\subsubsection{Profits after the trial}

Taking first the case when the quality of drug $j$ is realized as high, i.e. when $h_{j}=\bar{h}_{j}$, and characterizing the marginal consumer, $\widehat{\theta}$, who is indifferent between drugs $i$ and $j$

$$
\begin{aligned}
u_{i}(\theta) & =u_{j}^{T, H}(\theta) \\
\theta h_{i}^{\alpha}+Y-P_{i} & =\theta \bar{h}_{j}^{\alpha}+Y-P_{j} \\
& \Rightarrow \widehat{\theta}=\frac{P_{j}-P_{i}}{\bar{h}_{j}^{\alpha}-h_{i}^{\alpha}},
\end{aligned}
$$

where $T$ denotes that uncertainty is resolved through a trial, and $H$ denotes that the quality of drug $j$ is realized as high. In this case - when $h_{j}=\bar{h}_{j}$ - firm $j$ will serve the upper end of the market and will charge a higher price: the demand for drugs $i$ and $j$ can be characterized by the location of $\widehat{\theta}$; that is, $D_{j}^{T, H}\left(P_{i}, P_{j}\right)=\bar{\theta}-\widehat{\theta}=\bar{\theta}-\left(P_{j}-P_{i}\right) /\left(\bar{h}_{j}^{\alpha}-h_{i}^{\alpha}\right)$ and $D_{i}^{T, H}\left(P_{i}, P_{j}\right)=\widehat{\theta}-\bar{\theta}=\left(P_{j}-P_{i}\right) /\left(\bar{h}_{j}^{\alpha}-h_{i}^{\alpha}\right)-\bar{\theta}$. The two firms face the following profit maximization problem

$$
\max _{P_{k}} \pi_{k}^{T, H}=\left(P_{k}-c\right) D_{k}^{T, H}\left(P_{i}, P_{j}\right),
$$

where $k=i, j$. When the quality of drug $j$ is realized as high the equilibrium profits become

$$
\begin{aligned}
\pi_{j}^{T, H} & =\frac{(2 \bar{\theta}-\underline{\theta})^{2}}{9}\left(\bar{h}_{j}^{\alpha}-h_{i}^{\alpha}\right), \\
\pi_{i}^{T, H} & =\frac{(\bar{\theta}-2 \underline{\theta})^{2}}{9}\left(\bar{h}_{j}^{\alpha}-h_{i}^{\alpha}\right) .
\end{aligned}
$$

In the other case when the quality of $\operatorname{drug} j$ is revealed as low, i.e. where $h_{j}=\underline{h}_{j}$, equilibrium profits are obtained by setting up similar profit maximization problems. By first deriving the demand functions $D_{i}^{T, L}\left(P_{i}, P_{j}\right)$ and $D_{j}^{T, L}\left(P_{i}, P_{j}\right)$ —where $L$ denotes that drug $j$ has a low quality — and taking first order conditions the equilibrium profits are obtained as

$$
\begin{aligned}
\pi_{j}^{T, L} & =\frac{(\bar{\theta}-2 \underline{\theta})^{2}}{9}\left(h_{i}^{\alpha}-\underline{h}_{j}^{\alpha}\right), \\
\pi_{i}^{T, L} & =\frac{(2 \bar{\theta}-\underline{\theta})^{2}}{9}\left(h_{i}^{\alpha}-\underline{h}_{j}^{\alpha}\right) .
\end{aligned}
$$

It is interesting to note that when the quality of $\operatorname{drug} j$ is revealed as high a trial will always generate a larger diversity between the high and the low quality, and with more diversified drugs there will be higher profits in both ends of the market. In other words, both firm $i$ - in the upper end of the market — and firm $j$ - in the low end of the market — will earn 
higher profits after the trial ( $\pi_{j}^{T, H}$ and $\pi_{i}^{T, H}$ respectively) than they would in the no-trial case $\left(\pi_{j}^{N T}\right.$ and $\pi_{i}^{N T}$ respectively).

When a trial reveals the quality of $\operatorname{drug} j$ to be low, however, the profits of firm $i$ and $j$ can either increase or decrease depending on how differentiated the market becomes when uncertainty is resolved $\left(h_{i}^{\alpha}-\underline{h}_{j}^{\alpha}\right)$.

\subsubsection{Expected profits before the trial}

Taking expectations over profits in the different realizations - equations (10)-(13) - the exante profits when uncertainty is revealed becomes

$$
\begin{aligned}
E\left(\pi_{j}^{T}\right) & =p \pi_{j}^{T, L}+(1-p) \pi_{j}^{T, H} \\
& =p \frac{(\bar{\theta}-2 \underline{\theta})^{2}}{9}\left(h_{i}^{\alpha}-\underline{h}_{j}^{\alpha}\right)+(1-p) \frac{(2 \bar{\theta}-\underline{\theta})^{2}}{9}\left(\bar{h}_{j}^{\alpha}-h_{i}^{\alpha}\right), \\
E\left(\pi_{i}^{T}\right) & =p \pi_{i}^{T, L}+(1-p) \pi_{i}^{T, H} \\
& =p \frac{(2 \bar{\theta}-\underline{\theta})^{2}}{9}\left(h_{i}^{\alpha}-\underline{h}_{j}^{\alpha}\right)+(1-p) \frac{(\bar{\theta}-2 \underline{\theta})^{2}}{9}\left(\bar{h}_{j}^{\alpha}-h_{i}^{\alpha}\right) .
\end{aligned}
$$

Now, it is important to note that a Phase IV trial also has a cost, $\Omega$, which is carried by a firm that is performing the trial. This implies that a firm that is carrying out a trial has an expected profit of $E\left(\pi_{k}^{T}\right)-\Omega$, where $k=i, j$, while the rival will have an expected profit of $E\left(\pi_{-k}^{T}\right)$.

\subsection{Comparing profits with and without trial}

The next issue is whether elimination of quality uncertainty will benefit firms and whether the market voluntarily will eliminate the uncertainty. Addressing this with a standard duopoly model with vertical product differentiation first leads us to the following proposition.

Proposition 1 In a duopoly with vertical quality differentiation both firms will always earn higher expected profits when quality differences are eliminated than when quality differences remain uncertain, given that the firms do not have to carry the cost of the clinical trial.

Proof. The gain in profit for firm $j$ when uncertainty is eliminated is obtained by taking the difference between equations (14) and (7)

$$
E\left(\pi_{j}^{T}\right)-\pi_{j}^{N T}=p \frac{(\bar{\theta}-2 \underline{\theta})^{2}+(2 \bar{\theta}-\underline{\theta})^{2}}{9}\left(h_{i}^{\alpha}-\underline{h}_{j}^{\alpha}\right)>0
$$

which is positive. Hence, firm $j$ 's expected profits are increased when quality differences are disclosed. 
Similarly, firm i's profit gain when uncertainty is resolved is obtained by taking the difference between equations (15) and (8)

$$
E\left(\pi_{i}^{T}\right)-\pi_{i}^{N T}=p \frac{(2 \bar{\theta}-\underline{\theta})^{2}+(\bar{\theta}-2 \underline{\theta})^{2}}{9}\left(h_{i}^{\alpha}-\underline{h}_{j}^{\alpha}\right)>0
$$

which is positive. Firm $i$ will also increase its expected profits when quality differences are disclosed.

This implies that there is no strategic reason for firms to prefer quality uncertainty over quality certainty, as both firms ex ante would prefer a state where quality uncertainty were eliminated. To understand this result, first note that the basic mechanism generating economic profits in a duopoly market with vertical product differentiation is heterogeneity in quality. By resolving uncertainty the expected quality difference between drugs $i$ and $j$ is increased, and with larger differences in quality, profits are higher both in the upper and the lower end of the market.

With quality uncertainty firm $j$ is serving the upper end of the market with a moderate quality advantage based on the expected quality of $\operatorname{drug} j$. In the event that its quality is revealed as high, however, drug $j$ gains a considerable quality advantage over drug $i$; since, $h_{i}<\widetilde{h}_{j}<\bar{h}_{j}$. Thereby firm $j$ receives a substantial increase in profits. If, on the other hand, the quality of drug $j$ is unveiled as low, firm $j$ takes over the lower end of the market. This implies that firm $j$ may face a reduction in profits as it goes from serving the upper to the lower end of the market. Still, the reduction in profits - by ending up in the lower end of the market - will be less than proportional than its probability of actually ending up there. The clinical trial can thus be described as a lottery where the expected value of the gamble is higher than the price of the lottery ticket. This is illustrated in in figure 2 where the profit functions $\pi_{j}^{T, L}\left(h_{i}^{\alpha}-\underline{h}_{j}^{\alpha}\right)$ and $\pi_{j}^{T, H}\left(\bar{h}_{j}^{\alpha}-h_{i}^{\alpha}\right)$ - equations (12) and (10) respectively-are displayed. Since $\pi_{j}^{N T}$ (equation 7) is located on the $\pi_{j}^{T, H}$-line, it is always below expected profis in the no-trial case; ie., below the dashed line between $\pi_{j}^{T, L}$ and $\pi_{j}^{T, H}$.

For firm $i$ the gain from elimination of uncertainty is easily seen. If firm $i$ continues to serve the low quality segment of the market after the uncertainty is eliminated, it will have a larger quality disadvantage, which will give greater market power and thus higher profits. If the quality of $\operatorname{drug} j$ is revealed as low, on the other hand, firm $i$ will capture the upper end of the market and will potentially earn higher profits. If the heterogeneity in quality is sufficiently small, however, firm $i$ may well reduce its profits, but this reduction in profit is always less than proportional to the probability of capturing the upper end of the 


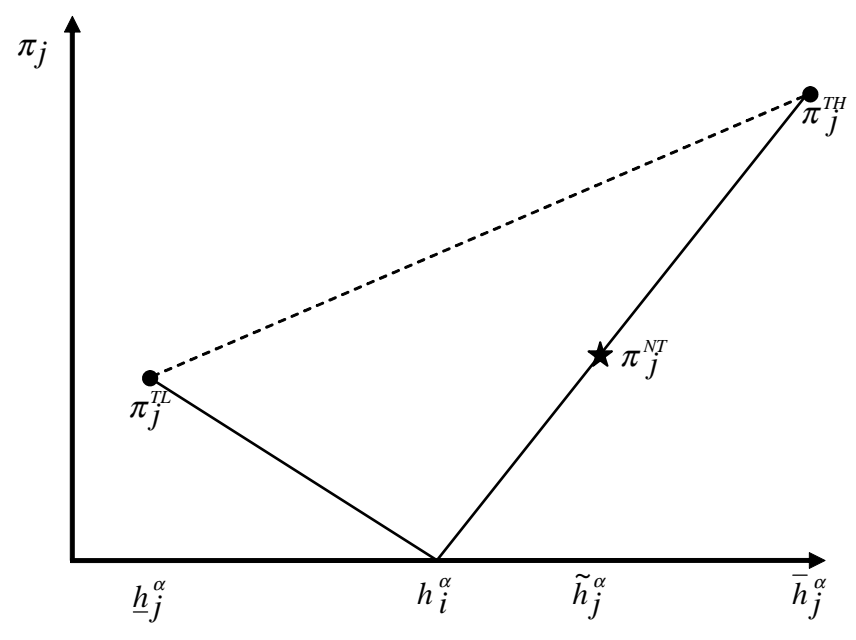

Figure 2: Profit Realizations in Different States for firm j.

market. Firm $i$ 's gain from elimination of uncertainty is illustrated in figure 3, where the profit functions $\pi_{i}^{T, H}\left(h_{i}^{\alpha}-\underline{h}_{j}^{\alpha}\right)$ and $\pi_{i}^{T, L}\left(\bar{h}_{j}^{\alpha}-h_{i}^{\alpha}\right)$ - equations (11) and (13) respectively-are displayed. The profit without trial $\pi_{i}^{N T}$ (equation 8), located on the $\pi_{i}^{T, L}$-line, is always below the dashed line between $\pi_{i}^{T, H}$ and $\pi_{i}^{T, L}$.

Ex-ante both firms would be better off if quality uncertainty is removed, but ex-postafter quality information is diclosed — both firms may in fact be worse-off.

A next issue is whether firms in the market have incentives to voluntarily perform informative clinical trials that eliminate uncertainty. The model provides the following proposition.

Proposition 2 Because it carries a cost $\Omega$ to perform a Phase IV clinical trial, there is no unique equilibrium where the market will provide information disclosure.

(i) If the trial cost is sufficiently small $E\left(\pi_{k}^{T}\right)-\Omega-\pi_{k}^{N T}-\Omega>0$, where $k=i, j$, there are two pure strategy Nash equilibria where only firm $i$ or only firm $j$ performs a trial.

(ii) If the trial cost is sufficiently large $E\left(\pi_{j}^{T}\right)-\Omega-\pi_{j}^{N T}<0$, where $k=i, j$, there is no equilibrium where a clinical trial is carried out.

Proof. (i) When $E\left(\pi_{k}^{T}\right)-\Omega-\pi_{k}^{N T}-\Omega>0$ the decision whether to perform a trial is characterized as a one-shot simultaneous move binary choice game with two players; that is, firm $i$ and firm $j$. The action space of the two players is $T$ and $N T$. The payoffs of firm $k$, where $k=i, j$, is $E\left(\pi_{k}^{T}\right)-\Omega$ when performing a trial, $E\left(\pi_{k}^{T}\right)$ when only firm $-k$ is performing a trial, and $\pi_{k}^{N T}$ when none of the firms are carrying out a trial. This game has two pure strategy Nash equilibria (firm $i$ is performing a trial, firm $j$ is not performing a 


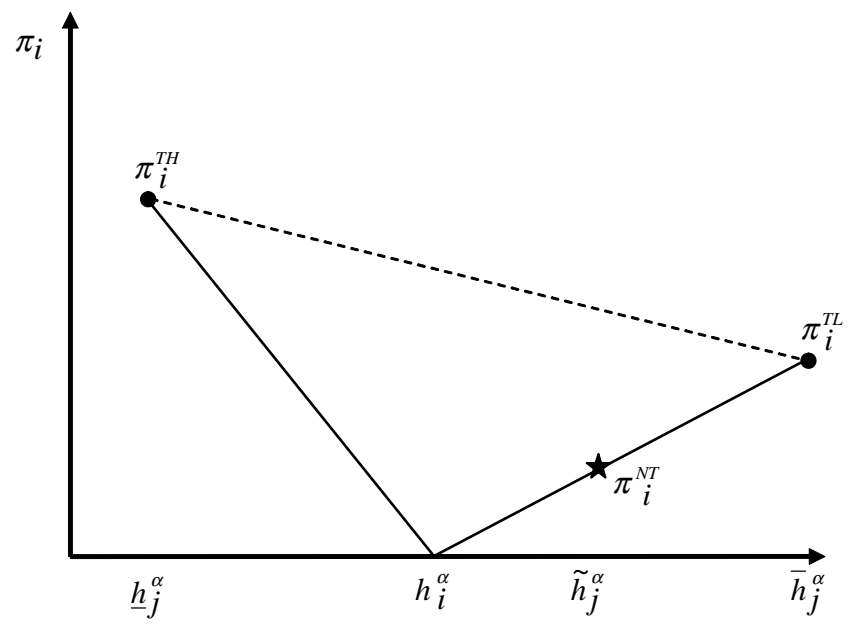

Figure 3: Profit Realizations in Different States for firm i.

trial) and (firm $i$ is not performing a trial, firm $j$ is performing a trial).

(ii) Follows directly from $E\left(\pi_{j}^{T}\right)-\Omega-\pi_{j}^{N T}<0$, where $k=i, j$.

When the cost of performing a trial is small, $E\left(\pi_{k}^{T}\right)-\Omega-\pi_{k}^{N T}>0$ with $k=i, j$, both firms would increase their expected profits by unilaterally performing a trial, but face a coordination problem since the rival firm would increase its profits even more by not performing a trial; that is, the rival would benefit from elimination of uncertainty but would not have to carry the trial cost. Both firms want uncertainty to be eliminated, but want their rival to defray the cost of the trial. Therefore there is no unique equilibrium where the market voluntarily provides elimination of uncertainty: in the two equilibriums either firm $i$ or firm $j$ performs a trial. ${ }^{9}$ As firms cannot coordinate their actions we may end up in an outcome where no trial is performed, or where both firms are carrying out trials.

In the other case, when the cost of performing is high, $E\left(\pi_{k}^{T}\right)-\Omega-\pi_{k}^{N T}>0$ with $k=i, j$, both firms would reduce their expected profits by unilaterally performing a trial. The high cost for eliminating uncertainty is a deterrent, and therefore no trial will be carried out.

With a cost $\Omega$ of performing a Phase IV trial, there is no unique equilibrium where the market is eliminating the quality uncertainty, either the cost leads to a coordination problem where each firm wants its rival to carry out the trial, or the cost is prohibitively high.

\footnotetext{
${ }^{9}$ The results are obtained for firms playing pure strategies only, and we have established that there is a coordination problem due to multiple pure strategy equilibria. As mixed strategies do not overcome this problem, they are not considered.
} 
Corollary 3 A legislation obliging enterant drug companies to carry out informative Phase IV clinical trials when launching a new drug will

(i) increase expected profits for the firms in the market if $E\left(\pi_{k}^{T}\right)-\Omega-\pi_{k}^{N T}>0$, but

(ii) reduce expected profits for the entrant firm if $E\left(\pi_{k}^{T}\right)-\Omega-\pi_{k}^{N T}<0$.

In the case where trial costs are low, $E\left(\pi_{k}^{T}\right)-\Omega-\pi_{k}^{N T}>0$, the regulation solves the coordination problem by coordinating the firms to one of the Nash equilibria; that is, the equilibrium where the entrant firm $j$ performs the trial. Both firms are better off with the regulation since their expected profits increase when quality information is revealed through the trial.

When trial costs are high however, $E\left(\pi_{k}^{T}\right)-\Omega-\pi_{k}^{N T}<0$, the entrant, firm $j$, would lose from the regulation as its expected profit would be reduced. The incumbent, firm $i$, would on the other hand benefit from information disclosure without having to bear its cost. Even if the incumbent gains from the disclosure total profits in the market are reduced by the legislation.

If trial costs are really high, $E\left(\pi_{k}^{T}\right)-\Omega<0$, a legislation can even hamper technological development. A trial would make the project of developing the drug unprofitable, and if firm $j$ chooses not to enter the market consumers will not have the chance of benefiting from the higher expected quality of drug $j$ - a quality $\bar{h}_{j}$ with probability $p$. This would also reduce competition in the pharmaceutical market for this particular condition as firm $i$ would keep its monopoly.

\section{Consumer welfare}

Both firm $i$ and firm $j$ have incentives to perform a Phase IV study, but to understand if a trial is beneficial to consumers we ask: what would consumers decide if they had a say in whether the trial should be carried out? To address the welfare consequences of Phase IV trials we will first calculate the consumer surplus when no trial is performed, and then compare this with the expected ex-ante consumer surplus when uncertainty is cleared away.

\subsection{Consumer surplus when no trial is performed}

If no trial is performed firm $j$ supplies the upper end of the market as $\widetilde{h}_{j}^{\alpha}>h_{i}^{\alpha}$. To find the expected consumer surplus generated by drug $j$ first note that the maximum price a consumer with preferences $\theta$ is prepared to pay for $\operatorname{drug} j$ is the total where all consumer 
surplus is exactly exhausted. That is, the reservation price $P_{j}^{R}$ is the price where the utility from consuming drug $j$ is just equal to the utility from not consuming any medicament, and is obtained as

$$
\begin{aligned}
u_{j} \text { (At the reservation price) } & =u(\text { When not consuming any drug }) \\
\theta \widetilde{h}_{j}^{\alpha}+Y-P_{j}^{R} & =Y \\
P_{j}^{R} & =\theta \widetilde{h}_{j}^{\alpha} .
\end{aligned}
$$

The expected surplus for a consumer $\theta$ can be defined as the utility obtained from drug $j$ at the actual price $P_{j}$ relative to the utility obtained at the reservation price, $P_{j}^{R}$, that is

$$
\begin{aligned}
E\left(C S_{j}^{N T}(\theta)\right) & =\left[\theta \widetilde{h}_{j}^{\alpha}+Y-c-\frac{(2 \bar{\theta}-\underline{\theta})}{3}\left(\widetilde{h}_{j}^{\alpha}-h_{i}^{\alpha}\right)\right]-\left[\theta \widetilde{h}_{j}^{\alpha}+Y-\theta \widetilde{h}_{j}^{\alpha}\right] \\
& =\theta \widetilde{h}_{j}^{\alpha}-c-\frac{(2 \bar{\theta}-\underline{\theta})}{3}\left(\widetilde{h}_{j}^{\alpha}-h_{i}^{\alpha}\right) .
\end{aligned}
$$

This is an expected consumer surplus since consumers do not know the actual quality of drug $j$, only its expected quality. By summing the surplus over all individuals in the high quality segment; that is, consumers $\theta \in(\widehat{\theta}, \bar{\theta})$, the aggregate surplus generated by drug $j$ is obtained as

$$
\begin{aligned}
E\left(C S_{j}^{N T}\right) & =\int_{\widehat{\theta}}^{\bar{\theta}}\left[\theta \widetilde{h}_{j}^{\alpha}-c-\frac{(2 \bar{\theta}-\underline{\theta})}{3}\left(\widetilde{h}_{j}^{\alpha}-h_{i}^{\alpha}\right)\right] d \theta \\
& =\frac{6 \bar{\theta} \underline{\theta}-3 \underline{\theta}^{2}}{18} \widetilde{h}_{j}^{\alpha}-\frac{2 \bar{\theta}-\underline{\theta}}{3} c+\frac{8 \bar{\theta}^{2}+2 \underline{\theta}^{2}-8 \bar{\theta} \underline{\theta}}{18} h_{i}^{\alpha} .
\end{aligned}
$$

In the same way the consumer surplus generated by drug $i$ becomes

$$
E\left(C S_{i}^{N T}\right)=\frac{3 \bar{\theta}^{2}-6 \bar{\theta} \underline{\theta}}{18} h_{i}^{\alpha}-\frac{\bar{\theta}-2 \underline{\theta}}{3} c-\frac{2 \bar{\theta}^{2}+8 \underline{\theta}^{2}-8 \bar{\theta} \underline{\theta}}{18} \widetilde{h}_{j}^{\alpha}
$$

\subsection{Consumer surplus when trial is performed}

When the uncertainty of drug $j$ 's quality is cleared away it is either high or low. To find the expected ex-ante consumer surplus we first have to calculate the consumer surpluses in the different realizations and then take the expectations over the realizations. 
If $\operatorname{drug} j$ is realized as being of high quality, i.e. $h_{j}=\bar{h}_{j}$, its reservation price - at which agents' are indifferent between consuming drug $j$ and not consuming any drug-becomes

$$
P_{j}^{R}=\theta \bar{h}_{j}^{\alpha}
$$

The surplus from good $j$ for an agent $\theta$ - defined as the difference in utility obtained at the actual price and at the reservation price - can therefore be defined in the following way

$$
\begin{aligned}
C S_{j}^{T, H}(\theta) & =\left[\theta \bar{h}_{j}^{\alpha}+Y-c-\frac{(2 \bar{\theta}-\underline{\theta})}{3}\left(\bar{h}_{j}^{\alpha}-h_{i}^{\alpha}\right)\right]-\left[\theta \bar{h}_{j}^{\alpha}+Y-\theta \bar{h}_{j}^{\alpha}\right] \\
& =\theta h_{2}^{\alpha}-c-\left(\bar{h}_{j}^{\alpha}-h_{i}^{\alpha}\right) \frac{(2 \bar{\theta}-\underline{\theta})}{3} .
\end{aligned}
$$

The aggregate consumer surplus of $\operatorname{drug} j$ is obtained by summing over all consumers $\theta \in$ $(\widehat{\theta}, \bar{\theta})$ choosing drug $j$; that is,

$$
\begin{aligned}
C S_{j}^{T, H} & =\int_{\widehat{\theta}}^{\bar{\theta}}\left[\theta \bar{h}_{j}^{\alpha}-c-\left(\bar{h}_{j}^{\alpha}-h_{i}^{\alpha}\right) \frac{(2 \bar{\theta}-\underline{\theta})}{3}\right] d \theta \\
& =\frac{6 \bar{\theta} \underline{\theta}-3 \underline{\theta}^{2}}{18} \bar{h}_{j}^{\alpha}-\frac{2 \bar{\theta}-\underline{\theta}}{3} c+\frac{8 \bar{\theta}^{2}+2 \underline{\theta}^{2}-8 \bar{\theta} \underline{\theta}}{18} h_{i}^{\alpha} .
\end{aligned}
$$

In a corresponding way, the aggregated consumer surplus for drug $i$, and for the case when the quality of drug $j$ is realized as low $\left(h_{j}=\underline{h}_{j}\right)$ can be obtained as

$$
\begin{aligned}
C S_{i}^{T, H} & =\frac{3 \bar{\theta}^{2}-6 \bar{\theta} \underline{\theta}}{18} h_{i}^{\alpha}-\frac{\bar{\theta}-2 \underline{\theta}}{3} c-\frac{2 \bar{\theta}^{2}+8 \underline{\theta}^{2}-8 \bar{\theta} \underline{\theta}}{18} \bar{h}_{j}^{\alpha} . \\
C S_{j}^{T, L} & =\frac{3 \bar{\theta}^{2}-6 \bar{\theta} \underline{\theta}}{18} \underline{h}_{j}^{\alpha}-\frac{\bar{\theta}-2 \underline{\theta}}{3} c-\frac{2 \bar{\theta}^{2}+8 \underline{\theta}^{2}-8 \bar{\theta} \underline{\theta}}{18} h_{i}^{\alpha}, \\
C S_{i}^{T, L} & =\frac{6 \bar{\theta} \underline{\theta}-3 \underline{\theta}^{2}}{18} h_{i}^{\alpha}-\frac{2 \bar{\theta}-\underline{\theta}}{3} c+\frac{8 \bar{\theta}^{2}+2 \underline{\theta}^{2}-8 \bar{\theta} \underline{\theta}}{18} \underline{h}_{j}^{\alpha} .
\end{aligned}
$$

The expected consumer surplus generated by drug $k$ is equal to

$$
E\left(C S_{k}^{T}\right)=p C S_{k}^{T, L}+(1-p) C S_{k}^{T, H},
$$

where $k=i, j$.

\subsubsection{Comparing consumer surpluses}

To determine whether consumers gain from more information on quality we now compare aggregated expected consumer surplus from lifting the quality uncertainty, with the aggregate consumer surplus from the expected quality when no clinical trial is performed. The result is summarized in the following proposition. 
Proposition 4 Consumers are worse-off if uncertainty about quality is eliminated.

Proof. The effect on aggregate consumer surplus from performing a trial — with firm $j$ serving the upper end of the market in the no-trial case - is obtained as

$$
\begin{aligned}
& E\left(C S_{i}^{T}\right)+E\left(C S_{j}^{T}\right)-E\left(C S_{i}^{N T}\right)-E\left(C S_{j}^{N T}\right) \\
= & \left(\underline{h}_{j}^{\alpha}-h_{i}^{\alpha}\right) \frac{13 \bar{\theta}^{2}+13 \underline{\theta}^{2}-28 \bar{\theta} \underline{\theta}}{18} p<0,
\end{aligned}
$$

which is negative under the assumption that $\bar{\theta}-2 \underline{\theta}>0$; i.e., the assumption that consumer preferences are sufficiently heterogenous for the market to cover both firms.

Agents will not gain from a trial ex-ante; that is, all consumers prefer that quality remains uncertain rather than being resolved through a Phase IV clinical trial. What proposition 3 says is that with risk averse agents the consumer surplus over expected quality is higher than the expected consumer surplus over realized quality. The expected quality will not increase with a trial, but the expected dispersion in quality will increase, and as a result the expected prices will increase after a trial. Before the trial consumers do not know the realizations that will follow - whether $h_{j}$ is high or low - they only know that they for certain will face higher expected prices. Ex-post they may very well gain from a trial if drug $j$ is revealed as a high quality drug - as the average drug quality in the market increases - but this is not certain.

Corollary 5 A legislation obliging pharmaceuticals to carry out Phase IV clinical trials - in order to establish relative effectiveness - when launching a new drug is harmful to consumers.

Consumers would ex-ante prefer a state without legislation that forces an entrant, firm $j$, to disclose quality information; to a state with legislation, as they are better-off under information uncertainty. In the case when the cost of the trial is so high that firm $j$ would choose not to enter the market if forced to perform a trial, $E\left(\pi_{k}^{T}\right)-\Omega<0$, the legislation would still be harmful to consumers. Since firm $j$ does not enter the market - as a consequence of the regulation - firm $i$ can charge monopoly prices.

\section{Discussion}

The market for prescription drugs is one of the most heavily regulated markets. Having a drug approved by the FDA and EMEA involves sending a truckload of documentation on the efficacy, safety and tolerability of the drug. Every step taken when developing the drug 
is scrutinized. There is a constant discussion on whether to introduce additional regulation; one such discussion is a legislation demanding entrant firms to carry out head-to-head clinical trials with competing drugs, in order to establish which drug is more effective. This paper analyses whether this is a good idea: we find that it is not. The purpose of such legislation would be to protect consumers, providing them with all the necessary information to make a fully-informed choice on which drug to use. However, eliminating uncertainty comes with a price that consumers do not want to pay.

The second reason why the legislation is a bad idea is that it will be costly: developing a new drug carries high costs, where the bulk of these costs consist of taking drugs through clinical trials (DiMasi, 2003). A large part of trial costs comes from paying doctors per patient they enrol, so trial costs rise fast with the number of patients taking part in the trial. Demanding firms to carry out head-to-head trials will increase these costs substantially as trials will have to be much larger to achieve statistically significant differences. For a block-buster drug this may be worth doing, but for drugs treating rare diseases it may prove prohibitive.

The model rests on the critical assumption that firms compete on price and the more differentiated products are, the larger mark-ups will be. There are a number of empirical papers studying whether differences in quality (effectiveness, side effects, safety, tolerability) are reflected in drug prices. A consistent finding is that drugs which represent important therapeutic gains, are priced significantly higher than existing drugs used for the same purpose (e.g. Ekelund and Persson, 2003; Lu and Comanor, 1995). They also find that drugs which largely duplicate actions of currently available drugs are typically priced at comparable levels, which is in accordance with our model. These papers provide some empirical support for the assumptions of the model; i.e. that quality differences are one of the major determinants of drug prices.

The relation between quality and prices has not been analyzed empirically in the pharmaceutical market. There are some papers studying price change over time, e.g. Lu and Comanor (1995), and what is important in the present context is that there seems to be considerable price movements over time. 


\section{References}

Angell M., 2004 , "The Truth About the Drug Industry: How They Deceive Us and What to Do About It", Random House, New York.

Armstrong D., Talley N.J., Lauritsen K., et al. "The role of acid supresson in patients with endoscope-negative reflux disease: the effect of treatment with esomeprazole or omepraozole", Aliment Pharmacol Ther. 2004:20:413-421.

Azoulay, P., 2002, "Do Pharmaceutical Sales Respond to Scientific Evidence?", Journal of Economics and Management Strategy, Vol. 11, pp. 551-594.

Bagwell, K. and Riordan, M.H., 1991, "High and Declining Prices Signal Product Quality", American Economic Review, Vol. 81, pp. 1156-1169.

Berndt E., Bhattacharjya A., Mishol D.N., Arcelus A. and Lasky T., 2002, "An Analysis of the Diffusion of New Antidepressants: Variety, Quality, and Marketing Efforts", The Journal of Mental Health Policy, Vol. 5, pp. 3-19.

Bernstein, A. and Bernstein, J., 2006, "The Information Prescription for Drug Regulation", Emory Public Law Research Paper No. 06-14

Bester, H., 1993, "Bargaining versus Price Competition in Markets with Quality Uncertainty", American Economic Review, 83, pp. 278-288.

Bester, H., 1998, "Quality Uncertainty Mitigates Product Differentiation”, RAND Journal of Economics, 29(4), pp. 828-844.

Castell D.O., Kahrilas P.J., Richter J.E., et al. "Esomeprazole (40 mg) compared with lansoprazole $(30 \mathrm{mg})$ in the treatment of erosive esophagitis", Am J Gastroenterol. 2002;97:575-83.

DiMasi J.A., Hansen R.W. and Grabowski H.G., 2003, "The price of innovation: new estimates of drug development costs", Journal of Health Economics, Mar;22(2):151-85.

Decoster G. and Buyse M., 1999, "Clinical Research after Drug Approval: What is Needed What is Not", Drug Information Journal, Vol. 33, pp. 627-634.

Ekelund M. and Persson B., 2003, "Pharmaceutical Pricing in a Regulated Market", The Review of Economics and Statistics, Vol. 85(2), pp. 298-306. 
Heres S., Davis J., Maino K., Jetzinger E., Kissling W. and Leucht S., 2006, "Why olanzapine beats risperidone, risperidone beats quetiapine, and quetiapine beats olanzapine: an exploratory analysis of head-to-head comparison studies of second-generation antipsychotics", Am J Psychiatry, Vol. 163(2):185-94.

Kahrilas P.J., Falk G.W., Johnson D.A., et al. "Esomeprazole improves healing and symptom resolution as compared with omeprazole in reflux esophagitis patients: a randomized controlled trial", Aliment Pharmacol Ther 2001;14:1249-1258

Labentz J., et al. "A comparison of esomeprazole $40 \mathrm{mg}$ once daily and pantoprazole once daily for the healing of reflux esophagitis", Gut 2003;52(Suppl VI):A241

Lexchin J., Bero L.A., Djulbegovic B. and Clark O., 2003, "Pharmaceutical industry sponsorship and research outcome and quality: systematic review", British Medical Journal, May 31;326(7400):1167-70.

Lu Z.J. and Comanor W.S., 1998, "Strategic Pricing of New Pharmaceuticals", The Review of Economics and Statistics, Vol. 80(1), pp. 108-118.

Melander H., Ahlqvist-Rastad J., Meijer G. and Beerman B., 2003, "Evidence B(i)ased Medicine-Selective Reporting from Studies Sponsored by Pharamaceutical Industry: review of Studies in New Drug Applications", British Medical Journal, Vol. 326 (May), pp. XX-XX.

Richter J.E., Kahrilas P.J., Johanson J et al. "Efficacy and safety of esomeprazole compared with omeprazole in GERD patients with erosive esophagitis: a randomized controlled trial", Am J Gastroenterol. 2001;96:656-65

Riordan M.H., 1986, "Monopolistic Competition with Experience Goods", Quarterly Journal of Economics, Vol. 101, pp. 265-279.

Rogerson W.P., 1988, "Price Advertising and the Deterioration of Product Quality", Review of Economic Studies, Vol. 55, pp. 215-229.

Schmalensee R., 1982, "Product Differentiation Advantages of Pioneering Brands", American Economic Review, Vol. 72, pp. 349-XX.

Shaked A. and Sutton J., 1982, "Relaxing Price Competition through Product Differentiation", Review of Economic Studies, Vol. 49, pp. 3-13. 
Wolinsky A., 1983, "Prices as Signals of Product Quality", Review of Economic Studies, vol. 50, pp. 647-658. 


\section{Appendix}

\section{A. Firm j entering in the low end of the market, $E\left(h_{j}^{\alpha}\right)<h_{i}^{\alpha}$}

\section{A.1 Profits in the no trial case}

Consider now the case when firm $j$ supples the lower end of the market (indicated by the superscript $j L E)$. This is when $E\left(h_{j}^{\alpha}\right)<h_{i}^{\alpha}$. Firm $j$ maximizes,

$$
\begin{aligned}
\max _{P_{j}} \pi_{j}^{N T, j L E} & =\left(P_{j}-c\right) D_{j}^{N T, j L E}\left(P_{i}, P_{j}\right) \\
& =\left(P_{j}-c\right)\left(\frac{P_{j}-P_{i}}{p \underline{h}_{j}^{\alpha}+(1-p) \bar{h}_{j}^{\alpha}-h_{i}^{\alpha}}-\underline{\theta}\right) .
\end{aligned}
$$

The first order condition is,

$$
\frac{2 P_{j}-P_{i}-c}{p \underline{h}_{j}^{\alpha}+(1-p) \bar{h}_{j}^{\alpha}-h_{i}^{\alpha}}-\underline{\theta}=0
$$

and rearranging gives firm $j$ 's reaction function

$$
R_{j}^{N T, j L E}\left(P_{i}\right)=\frac{P_{i}+c+\underline{\theta}\left(p \underline{h}_{j}^{\alpha}+(1-p) \bar{h}_{j}^{\alpha}-h_{i}^{\alpha}\right)}{2} .
$$

Firm i, on the other hand, maximizes,

$$
\begin{aligned}
\max _{P_{i}} \pi_{i}^{N T, j L E} & =\left(P_{i}-c\right) D_{i}^{N T, j L E}\left(P_{i}, P_{j}\right) \\
& =\left(P_{i}-c\right)\left(\bar{\theta}-\frac{P_{j}-P_{i}}{p \underline{h}_{j}^{\alpha}+(1-p) \bar{h}_{j}^{\alpha}-h_{i}^{\alpha}}\right),
\end{aligned}
$$

which yields the following first order condition,

$$
\bar{\theta}-\frac{P_{j}+c-2 P_{i}}{p \underline{h}_{j}^{\alpha}+(1-p) \bar{h}_{j}^{\alpha}-h_{i}^{\alpha}}=0 .
$$

Solving for $P_{i}$ gives firm $i$ 's reaction function,

$$
R_{i}^{N T, j L E}\left(P_{j}\right)=\frac{P_{j}+c-\bar{\theta}\left(p \underline{h}_{j}^{\alpha}+(1-p) \bar{h}_{j}^{\alpha}-h_{i}^{\alpha}\right)}{2} .
$$

Using $R_{i}$ and $R_{j}$ equilibrium prices are obtained,

$$
\begin{aligned}
P_{j}^{N T, j L E} & =c+\frac{(\bar{\theta}-2 \underline{\theta})}{3}\left(h_{i}^{\alpha}-p \underline{h}_{j}^{\alpha}-(1-p) \bar{h}_{j}^{\alpha}\right), \\
P_{i}^{N T, j L E} & =c+\frac{(2 \bar{\theta}-\underline{\theta})}{3}\left(h_{i}^{\alpha}-p \underline{h}_{j}^{\alpha}-(1-p) \bar{h}_{j}^{\alpha}\right) .
\end{aligned}
$$

Substituting equilibrium prices - equations (A.1) and (A.2) - into equation (3) yields,

$$
\widehat{\theta}=\frac{\bar{\theta}+\underline{\theta}}{3} \text {. }
$$


and thus the following equilibrium quantities,

$$
\begin{aligned}
Q_{j}^{N T, j L E} & =\frac{(\bar{\theta}-2 \underline{\theta})}{3}, \\
Q_{i}^{N T, j L E} & =\frac{(2 \bar{\theta}-\underline{\theta})}{3} .
\end{aligned}
$$

In equilibrium firm has the following profits,

$$
\begin{aligned}
& \pi_{j}^{N T, j L E}=\frac{(\bar{\theta}-2 \underline{\theta})^{2}}{9}\left(h_{i}^{\alpha}-p \underline{h}_{j}^{\alpha}-(1-p) \bar{h}_{j}^{\alpha}\right), \\
& \pi_{i}^{N T, j L E}=\frac{(2 \bar{\theta}-\underline{\theta})^{2}}{9}\left(h_{i}^{\alpha}-p \underline{h}_{j}^{\alpha}-(1-p) \bar{h}_{j}^{\alpha}\right) .
\end{aligned}
$$

\section{A.2 Consumer surplus in the no trial case}

Similarly, when firm $j$ supplies the lower end of the market; that is, $E\left(h_{j}^{\alpha}\right)<h_{i}^{\alpha}$, the aggregated consumer surplus of the two drugs becomes,

$$
\begin{aligned}
& E\left(C S_{j}^{N T, J L E}\right)=\frac{3 \bar{\theta}^{2}-6 \bar{\theta} \underline{\theta}}{18} \widetilde{h}_{j}^{\alpha}-\frac{\bar{\theta}-2 \underline{\theta}}{3} c-\frac{2 \bar{\theta}^{2}+8 \underline{\theta}^{2}-8 \bar{\theta} \underline{\theta}}{18} h_{i}^{\alpha} \\
& E\left(C S_{i}^{N T, J L E}\right)=\frac{6 \bar{\theta} \underline{\theta}-3 \underline{\theta}^{2}}{18} h_{i}^{\alpha}-\frac{2 \bar{\theta}-\underline{\theta}}{3} c+\frac{8 \bar{\theta}^{2}+2 \underline{\theta}^{2}-8 \bar{\theta} \underline{\theta} \widetilde{h}_{j}^{\alpha} .}{18} .
\end{aligned}
$$

\section{A.3 Comparing the cases: Trial vs. No trial}

\section{A.3.1 Differences in profits when $E\left(u_{j}^{N T}\right)<u_{i}$}

If firm $j$ is serving the lower end of the market when it enters under uncertainty, the difference in profits between the trial and the no-trial case for firm $j$ is obtained by taking the difference between equations (14) and (A.4),

$$
\begin{aligned}
E\left(\pi_{j}^{T}\right)-\pi_{j}^{N T, j L E}= & p \frac{(\bar{\theta}-2 \underline{\theta})^{2}}{9}\left(h_{i}^{\alpha}-\underline{h}_{j}^{\alpha}\right)+(1-p) \frac{(2 \bar{\theta}-\underline{\theta})^{2}}{9}\left(\bar{h}_{j}^{\alpha}-h_{i}^{\alpha}\right) \\
& -\frac{(\bar{\theta}-2 \underline{\theta})^{2}}{9}\left(h_{i}^{\alpha}-p \underline{h}_{j}^{\alpha}-(1-p) \bar{h}_{j}^{\alpha}\right) \\
= & (1-p) \frac{(\bar{\theta}-2 \underline{\theta})^{2}+(2 \bar{\theta}-\underline{\theta})^{2}}{9}\left(\bar{h}_{j}^{\alpha}-h_{i}^{\alpha}\right) \\
= & (1-p)\left[\pi_{i}^{T, j L E}+\pi_{j}^{T, j L E}\right]>0,
\end{aligned}
$$

and for firm i by taking the difference between equations (15) and (A.5), 


$$
\begin{aligned}
E\left(\pi_{i}^{T}\right)-\pi_{i}^{N T, j L E}= & p \frac{(2 \bar{\theta}-\underline{\theta})^{2}}{9}\left(h_{i}^{\alpha}-\underline{h}_{j}^{\alpha}\right)+(1-p) \frac{(\bar{\theta}-2 \underline{\theta})^{2}}{9}\left(\bar{h}_{j}^{\alpha}-h_{i}^{\alpha}\right) \\
& -\frac{(2 \bar{\theta}-\underline{\theta})^{2}}{9}\left(h_{i}^{\alpha}-p \underline{h}_{j}^{\alpha}-(1-p) \bar{h}_{j}^{\alpha}\right) \\
= & .(1-p) \frac{(2 \bar{\theta}-\underline{\theta})^{2}+(\bar{\theta}-2 \underline{\theta})^{2}}{9}\left(\bar{h}_{j}^{\alpha}-h_{i}^{\alpha}\right) \\
= & (1-p)\left[\pi_{i}^{T, j L E}+\pi_{j}^{T, j L E}\right]>0 .
\end{aligned}
$$

Ex-ante both firms gain by performing a trial that resolves uncertainty, even if they ex-post are bound to make results public.

\section{A.3.2 Differences in consumer surplus when $E\left(u_{j}^{N T}\right)>u_{i}$}

In the same way, when firm $\mathrm{j}$ is serving the lower end of the market in the baseline no-trial case, the difference in aggregated consumer surplus between trial and no-trial is,

$$
\begin{aligned}
& E\left(C S_{i}^{T}\right)+E\left(C S_{j}^{T}\right)-E\left(C S_{i}^{N T, J L E}\right)-E\left(C S_{j}^{N T, J L E}\right) \\
& =\left[\begin{array}{c}
h_{i}^{\alpha} \frac{11 \bar{\theta}^{2}+2 \underline{\theta}^{2}-14 \bar{\theta} \underline{\theta}}{18}-h_{i}^{\alpha} \frac{13 \bar{\theta}^{2}+13 \underline{\theta}^{2}-28 \bar{\theta} \theta}{18} p \\
+\underline{h}_{j}^{\alpha} \frac{11 \bar{\theta}^{2}+2 \underline{\theta}^{2}-14 \bar{\theta} \theta}{18} p-\bar{h}_{j}^{\alpha} \frac{2 \bar{\theta}^{2}+11 \underline{\theta}^{2}-14 \bar{\theta} \underline{\theta}}{18}(1-p)-c(\bar{\theta}-\underline{\theta})
\end{array}\right] \\
& -\left[\widetilde{h}_{j}^{\alpha} \frac{11 \bar{\theta}^{2}+2 \underline{\theta}^{2}-14 \bar{\theta} \underline{\theta}}{18}-h_{i}^{\alpha} \frac{2 \bar{\theta}^{2}+11 \underline{\theta}^{2}-14 \bar{\theta} \underline{\theta}}{18}-c(\bar{\theta}-\underline{\theta})\right] \\
& =\left(h_{i}^{\alpha}-\bar{h}_{j}^{\alpha}\right) \frac{13 \bar{\theta}^{2}+13 \underline{\theta}^{2}-28 \bar{\theta} \underline{\theta}}{18}(1-p)<0 .
\end{aligned}
$$

This difference is negative as $\bar{\theta}-2 \underline{\theta}>0$, which implies that the aggregate surplus is reduced when new information arrives. 